\title{
Screw removal torque evaluation in implants with cone morse and external hexagon platforms in anterior cantilever
}

Olinto Barbosa Figueiredo ${ }^{1}$

Carlos Eduardo Francischone ${ }^{2}$

Amanda Gonçalves Franco ${ }^{3}$

Geraldo Alberto Pinheiro de Carvalho ${ }^{4}$

Bruno Salles Sotto - Maior ${ }^{5}$

\section{ABSTRACT}

This study aims to evaluate the screw removal torque on prosthetic platforms of Cone Morse (CM) and External Hexagon (EH) implants in crowns with anterior cantilever. Materials and Methods: in vitro study with a sample consisting of 20 test specimens of 2 elements ( 21 and 22), with $n=40$; load is simulated on element 21 or on cantilever of 22 . Samples were divided into 4 groups consisting of 10 test specimens on CM implants (groups 1 and 2), and 10 test specimens on EH implants (groups 3 and 4). The test specimens were manufactured using cylindrical PVC pipes measuring $22 \times 19.05 \mathrm{~mm}$ filled with acrylic resin. The implants were fixed with a centralization device. Components used were EUCLAs and UCLAs with a chrome-cobalt alloy molten base. The metal bases were scanned, the crowns were digitally waxed, made on CAD/CAM system, and cemented on the metal bases with Panavia cement. Torque was applied using $20 \mathrm{~N}$ for $\mathrm{CM}$ and $32 \mathrm{~N}$ for $\mathrm{EH}$, according to the manufacturers' instructions. The test specimens were then subjected to a cycling process consisting of 1,000,000 cycles at a frequency of $2 \mathrm{~Hz}$. The cyclic process applied axial forces to the surface (pal- ate face of 21 and 22). Two cycling processes were carried on, the first on the palate face of 21 and the second on the palate face of 22. Between the two, screws were removed and replaced by new ones. The screw removal torque was measured using a digital torque meter. Results were analyzed with Student's t test and variance analysis. Statistical calculations were conducted in SPSS 23 using $5 \%$ of significance. Results: Student's t test showed significantly lower removal torque values in comparison with initial torque for both $\mathrm{CM}$ and $\mathrm{EH}$ connection implants and force applied to elements 21 and $22(p<0.001)$ or 22 ( $p<0.001)$. Considering torque loss, there was no significant effect of the interaction between type of implant connection and site of force application $(p=0.094)$. Removal torque was significantly lower than initial torque for both implants (CM and EH). Conclusion: Torque loss occurred both in $\mathrm{CM}$ and $\mathrm{EH}$. There was no significant effect of the interaction between connections and site of force application.

Keywords: countertorque. cantilever. cycling. implant.

\footnotetext{
${ }^{1}$ Department of Restorative Dentistry, São Leopoldo Mandic Research Center, Campinas, São Paulo, Brazil. Rua José Rocha Junqueira, 13, Ponte Preta. CEP:13045-755. Phone number: (19) 3111-3600.

${ }^{2}$ Department of Implantology, São Leopoldo Mandic Research Center, Campinas, São Paulo, Brazil. Rua José Rocha Junqueira, 13, Ponte Preta. CEP:13045755. Phone number: (19) 3111-3600

${ }^{3}$ University of Itaúna. Rodovia MG $431 \mathrm{Km} \mathrm{45,} \mathrm{s/n,} \mathrm{Itaúna,} \mathrm{Minas} \mathrm{Gerais.} \mathrm{CEP:} \mathrm{35680-142.} \mathrm{Phone} \mathrm{number:} \mathrm{(37)} \mathrm{99959-0164} \mathrm{Correspondencia} \mathrm{para} \mathrm{AG}$ FRANCO. E-mail: < amandagfranco38@gmail.com>

${ }^{4}$ Department of Restorative Dentistry, São Leopoldo Mandic Research Center, Campinas, São Paulo, Brazil. Rua José Rocha Junqueira, 13, Ponte Preta. CEP:13045-755. Phone number: (19) 3111-3600.

${ }^{5}$ Department of Restorative Dentistry, São Leopoldo Mandic Research Center, Campinas, São Paulo, Brazil. Rua José Rocha Junqueira, 13, Ponte Preta. CEP:13045-755. Phone number: (19) 3111-3600.
}

Como citar este artigo / How to cite this article

Figueiredo OB, Francischone CE, Franco AG, Carvalho GAP, Sotto-Maior BS. Screw removal torque evaluation in implants with cone morse and external hexagon platforms in anterior cantilever. InterAm J Med Health 2021;4:e202101029. 


\section{INTRODUCTION}

Rehabilitation of the anterior portion of the jaw involves funcional, biomechanic and aesthetic factors, and present several challenges. Thus, successful treatments with implant-supported prostheses require an understanding of the basic biomechanical principles, such as loosening of connection abutments, aesthetical and functional demands, and the patients expectations [1].

There are therapeutic options with implants for edentulous rehabilitation for elements 12 to 22 . Depending on the mesio-distal distance and vestibule palatine thickness of elements 13 to 23 , the possibilities are: 4 implants; 2 implants on the central positions and cantilevers on the lateral positions; 2 implants on the lateral positions and pontic on the central positions; 1 implant on 11 and 22 with pontic at the 21 and cantilever at 12; implant on 12 and 21 with pontic at the 11 and cantilever at 22 . Here, we simulate the absence of 21 and 22 using the therapeutic option of applying the implant on 21 with the cantilever on 22.

These local conditions can lead to two therapeutic options for the rehabilitation with implants: (1) regenerative / bone reconstruction procedures, or (2) conventional fixed prostheses, cantilever. The main disadvantage of cantilever prostheses is the disputable long-term mechanical strength; however, many dentists still use two regular implants on the central incisor position due to a larger bone area, and cantilever prostheses to replace the lateral incisors.

This type of prosthesis can be damaging in biomechanical terms. Literature related to partial fixed implant-supported prosthesis with cantilever is still scarce [2].

Replacement of upper or lower anterior teeth by implant-supported prostheses is challenging because mesio-distal and vestibule-lingual dimensions are so small that position and number of implants can be affected, which can, in turn, affect the definite prosthetic design [3].

Therefore, published results must be interpreted with caution, mainly because the use of a support arm is associated with a high incidence of complications, such as flexural movements by the lever arm, which can concentrate stress fields on the implant and bone, leading to a possible loosening or fracture of the screw, bone resorption and/or implant failure.

When loads are applied outside the long axis of the abutment/implant assembly, prosthetic complications occur. Currently, alternatives for implant installation in jaw edentulous should consider length, diameter, abutment/ implant connection, restoration material and applied load. These characteristics can influence the level of tension and distribution of loads, mainly on the interface bone-implant and this is directly related to screw loosening.

Given this scenario, it seems pertinent to evaluate screw removal torque in implants with Cone Morse and External Hexagon platforms in crowns with anterior cantilever subjected to mechanical cycling.

\section{MATERIALS AND METHODS}

\section{Experimental design}

This study was waived by the Research Ethics Committee of São Leopoldo Mandic University under protocol \# 2016/0642.

The experimental model is an in vitro assay on a sample consisting of 20 test specimens, $n=40$, divided into 4 groups (table 1).

Group 1: 10 screwed crowns on Strong Cone Morse implants measuring $3.8 \times 13 \mathrm{~mm}$ (SIN SISTEMA DE IMPLANTES; SÃO PAULO, SÃO PAULO, BRAZIL) (batches 0010120795 and 0020123577, Anvisa 80108910012, SÃO PAULO/BR), simulating the region of tooth 21 and cantilever on 22, and force applied to the palate face of 21, using molten base components EUCLAM 456C-H indexed (SIN SISTEMA DE IMPLANTES; SÃO PAULO, SÃO PAULO, BRAZIL) (batches 0050132556, T070291374, T020280085, T030284217 Anvisa 80108910033,SÃO PAULO/BR).

Group 2: 10 screwed crowns on SIN Cone Morse implants measuring $3.8 \times 13 \mathrm{~mm}$ (batches 010090523, 010090990, 0020123577, 0010120795, 080293097, R120242885, Anvisa 80108910009, SÃO PAULO/BR), simulating the region of tooth 21 and cantilever on 22, and force applied to the palate face of 22, using molten base components SIN EUCLAM 456C-H indexed (batches 0050132556, T070291374, T020280085, T030284217).

Group 3: 10 screwed crowns on SIN External Hexagon implants measuring $3.8 \times 13 \mathrm{~mm}$, (batches 010090523, 010090990, T030283394, Anvisa 80108910009, SÃO PAULO BR), simulating the region of tooth 21 and cantilever on 22, and force applied to the palate face of 21, using molten base components SIN EUCLAM 406-Q (batches 0050133222, R020218480, T070291374, Anvisa 80108910033, SÃO PAULO/BR).

Group 4: 10 screwed crowns on SIN External 
Table 1. Separation of the 4 groups.

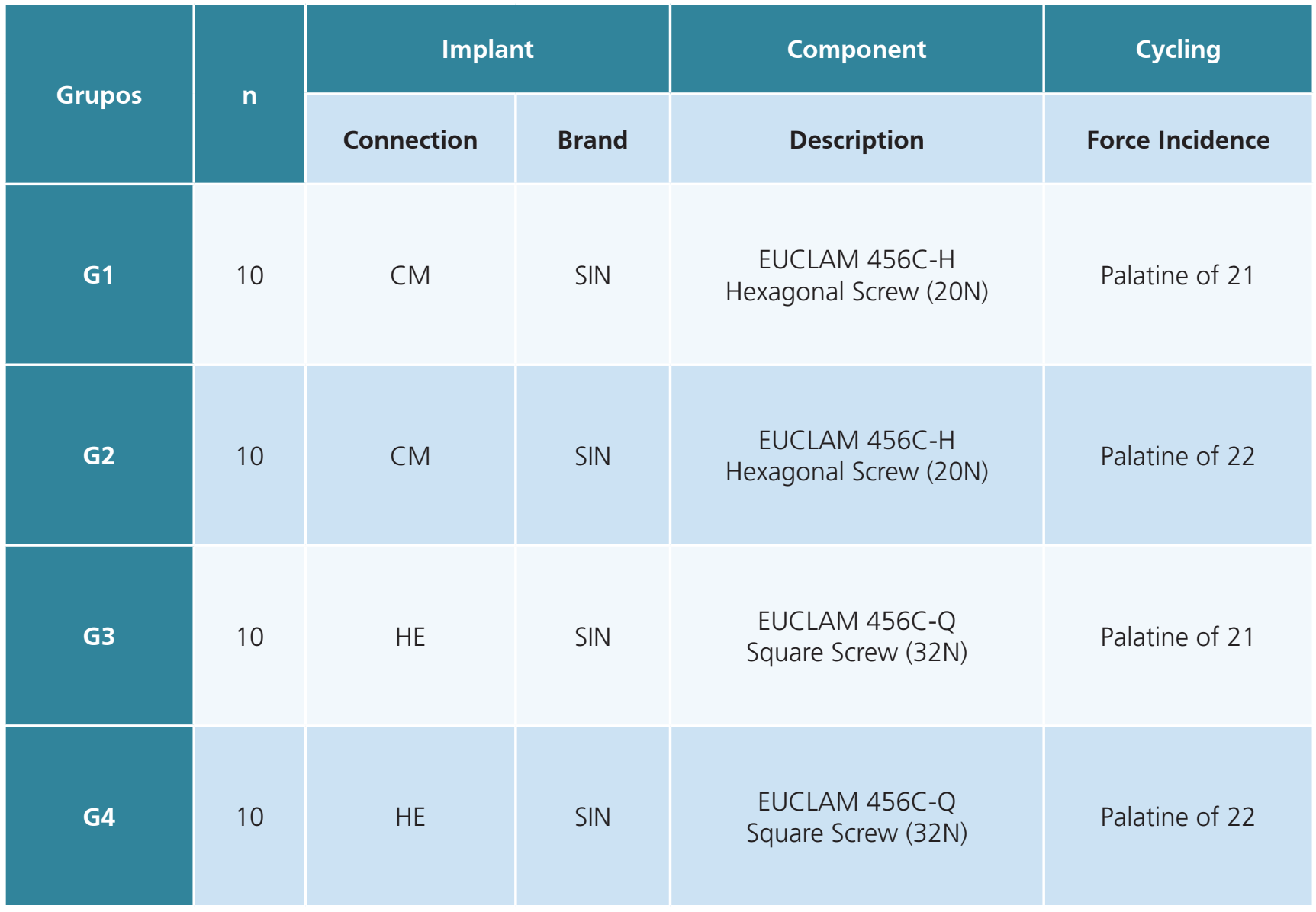

Source: Own authorship.

Hexagon implants measuring $3.8 \times 13 \mathrm{~mm}$ (batches 010090523, 010090990, T030283394, Anvisa 80108910009, SÃO PAULO/BR), simulating the region of tooth 21 and cantilever on 22, and force applied to the palate face of 22, using molten base components SIN EUCLAM 406-Q (batches 0050133222,R020218480, T070291374, Anvisa 80108910033, SÃO PAULO/BR).

\section{Manufacturing the test specimens}

The implants were fixed to 20 test specimens previously manufactured and standardized to fit the positioner bases of the cycling machine, with a platform system tilted 17 degrees (figure 1).

The test specimens were manufactured using cylindrical PVC pipes (Tigre, Rio Claro, São Paulo, Brazil) measuring $22 \times 19.05 \mathrm{~mm}$. The implants were then positioned straight on the center of the test specimen below the connection/implant platform level. Cylinders
Figure 1. Platform system tilted 17 degrees.

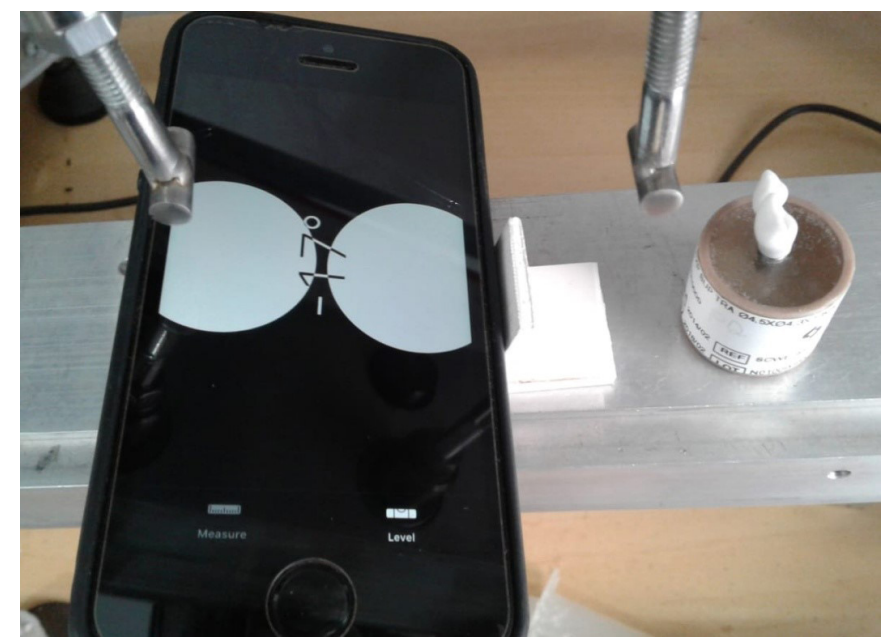

Source: Own authorship. 
were filled with acrylic resin (self-polymerizing acrylic Classic JET, Campo Limpo Paulista/SP). Once the adhesion of acrylic resin was satisfatory, the chrome-cobalt metal alloy base components were installed on the implants (figure 2 and 3).

Figure 2. 20 specimens. $10 \mathrm{CM}(\mathrm{A})$ and $10 \mathrm{HE}$ test specimens (B).

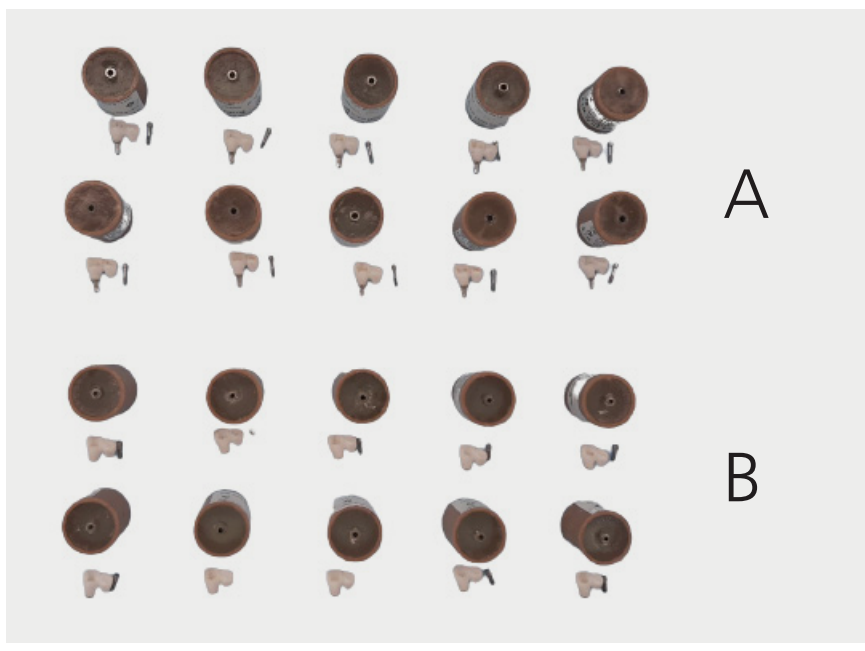

Source: Own authorship.

Figure 3. Top view of the $C M(A)$ and $H E(B)$ implants fixed with acrylic resin on the cylindrical PVC specimen.

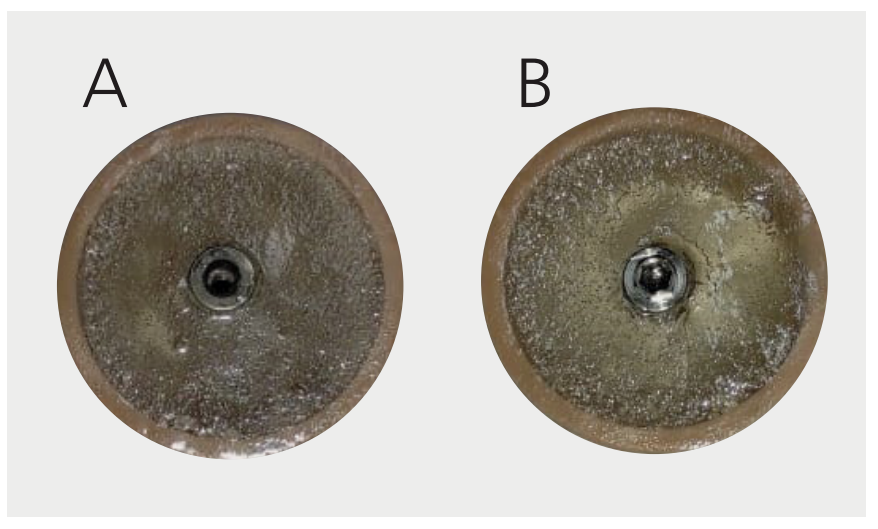

Source: Own authorship.

The test specimens were digitalized using a bench dental scanner (Scanner 7 series by dental wings). Using the software CARES visual 13 (Straumann), the teeth on regions 21 and 22 were projected (figure 4).
Using CAD/CAM (M Series Ceramill Motion II Straumann) system, the teeth were machined in zirconia (Ceramill Zl $71 \mathrm{~S} 14 \mathrm{~mm}$ ZRO2 Austria). Zirconia was cemented to the metal components using resin cement Panavia (F 2.0 Half Light - Kuraray, Kurashiki, Japan) (figure 5).

Figure 4. Test specimen with scanned $\operatorname{EUCLAM~(A),~}$ prosthetic wax-up of teeth 21 and 22 (B) and (C).

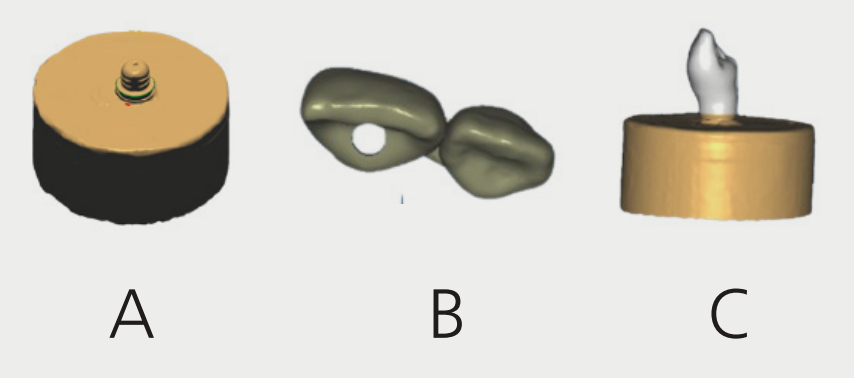

Source: Own authorship.

Figure 5. Milled Zirconia Teeth 21 and 22. Prosthetic crown cemented with Panavia on EUCLAM CM (A) and EUCLAM HE (B) components.
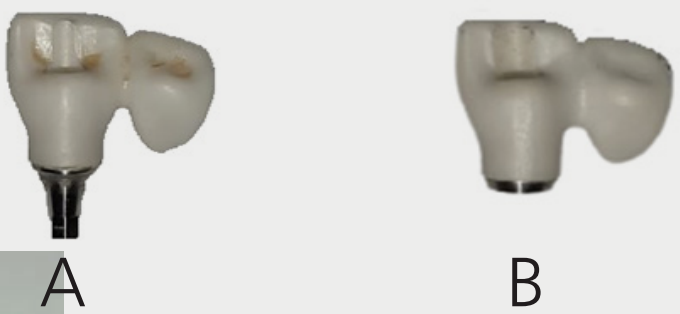

Source: Own authorship.

\section{Installing crowns on the test specimens}

To install the crowns on the test specimens, two types of screw drivers were used: PT 2006 and PTQ 2008 (SIN - SISTEMA DE IMPLANTE, SÃO PAULO, SÃO PAULO, BRAZIL). The crowns were screwed to the implants with Cone Morse platform using hexagonal screws, applying $20 \mathrm{~N}$ of torque, according to the manufacturer's recommendation. On implants with External Hexagon platform, the crowns were screwed using square screws, applying $32 \mathrm{~N}$ of torque, 
as per the manufacturer's instructions (figure 6).

Torque was measured using a digital torque meter (LUTRON TQ - 8800) (figure 7, 8 and 9)

Figure 7. Digital torque meter (LUTRON TQ - 8800).

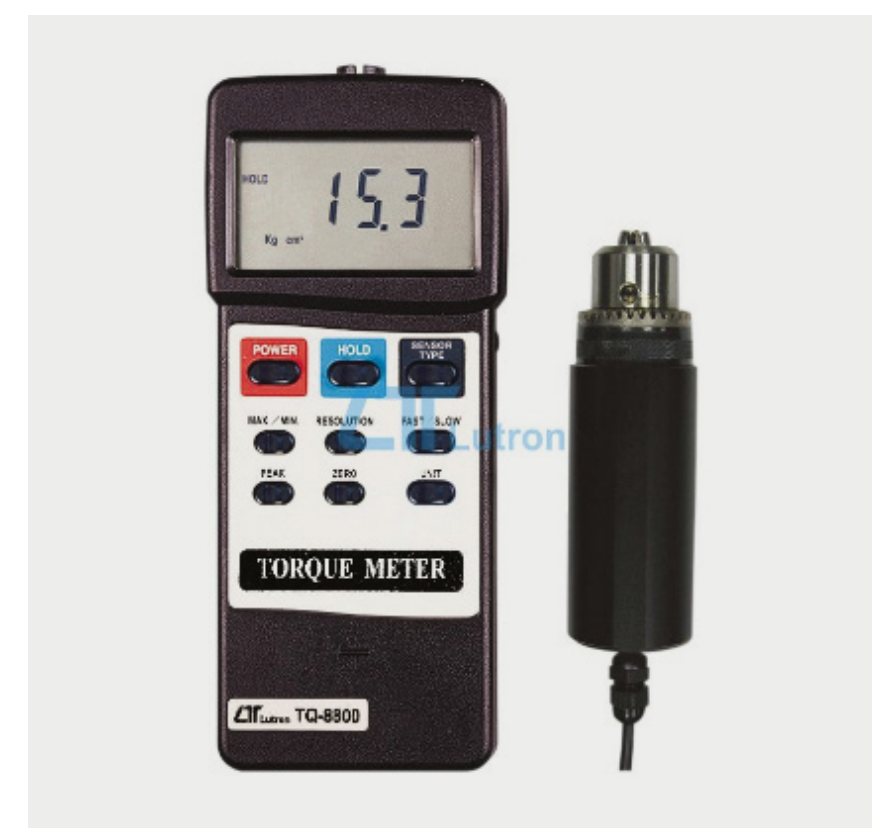

Source: Dental Materials Laboratory São Leopoldo Mandic.

Figure 8. $C M(A)$ and $H E(B)$ torqued specimen for first cycling.

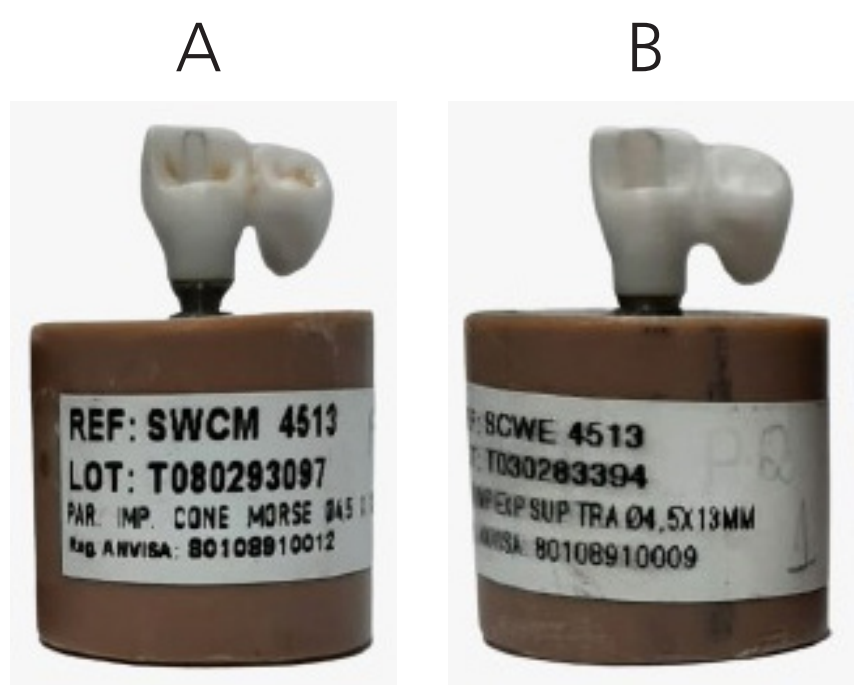

Source: Dental Materials Laboratory São Leopoldo Mandic.

\section{Mechanical tests}

The test specimens were fixed to the base of the cycling machine (fatigue simulator) for the cyclic force test. The specimens were subjected to $1 \times 106 \mathrm{~W}$ during the fatigue test, under dynamic axial loading of $130 \mathrm{~N}$ in an electromechanical machine of fatigue simulation (MSFM, Elquip, São Carlos, SP, Brazil) at a frequency of $2 \mathrm{~Hz}$. Counterpart is made of stainless steel 304 (figure 10, 11 and 12).

The cyclic process applied axial force to the surface (palate face of 21 and 22). Two cyclings were conducted, the first to the palate face of 21 and the second to the palate face of 22. Between first and second cyclings, the screws were removed and replaced by new ones, applying torque according to the manufacturers' instructions. The variable to be evaluated is the removal torque (unscrewing) using the digital torque meter. Load and number of cycles were read by a transducer coupled to a computerized system that monitors every tests.

Each test specimen was subjected to $1,000,000$ cycles, which corresponds to 1 year of masticatory effort. Following the mechanical test, the assemblies were separated for the evaluation of removal torque of the components. To measure counter-toque, the torque meter was employed counterclockwise until releasing the retention screw.

Results were subjected to descriptive statistical analysis, which showed differences in torque in all four groups.

\section{Statistical analysis}

Removal torque and torque loss were evaluated for normality and homoscedasticity. To check whether mechanical cycling reduced initial torque, groups were analyzed with the Student's t test for one sample. Torque loss was evaluated using two-way variance analysis to compare prosthetic platforms of Cone Morse and External Hexagon implants when stress is applied to elements 21 and 22 (cantilever).

All statistical calculations were conducted in SPSS 23 (SPSS INC., Chicago, IL, USA), considering 5\% of significance.

\section{RESULTS}

Student's $t$ test for one sample showed that removal torque was significantly lower than the initial 
Figure 9. First torque on the specimens for first cycling (palatal of 21).
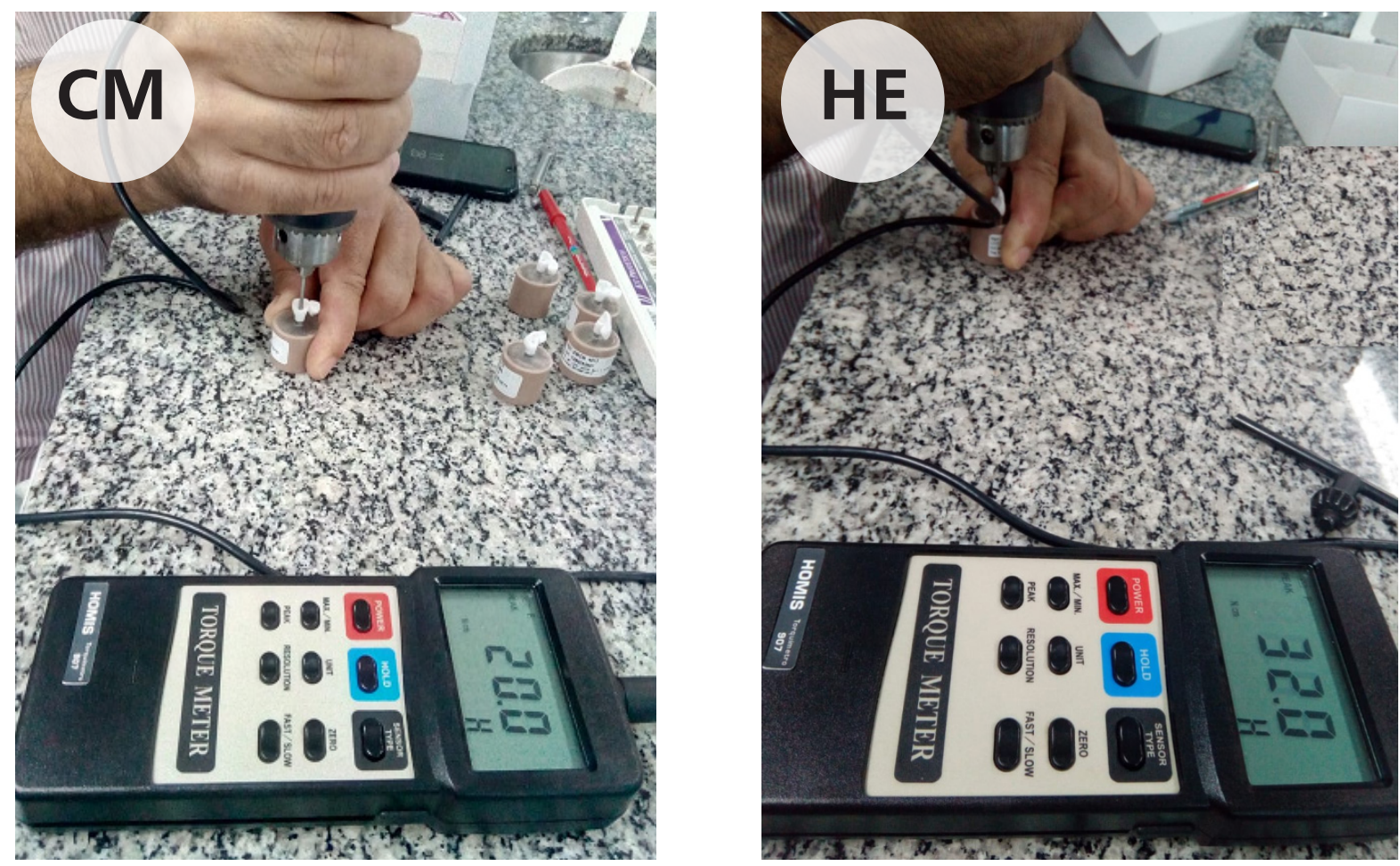

Source: Dental Materials Laboratory São Leopoldo Mandic.

Figure 10. Equipment used to simultate mastication fatigue $(A)$ and location of the incidence of force in the two cycles (B).

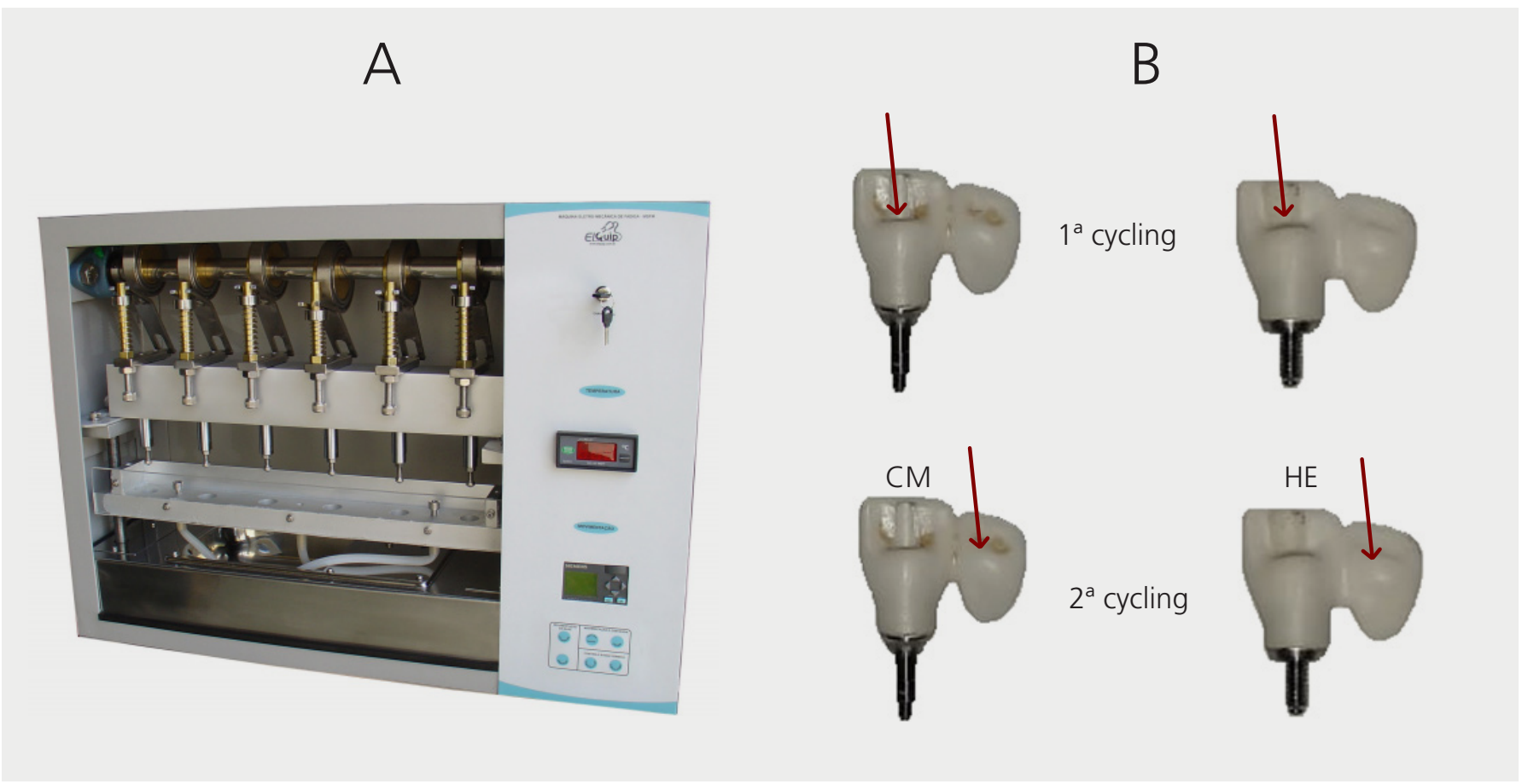


Figure 11. Calculation of results after the first cycle.
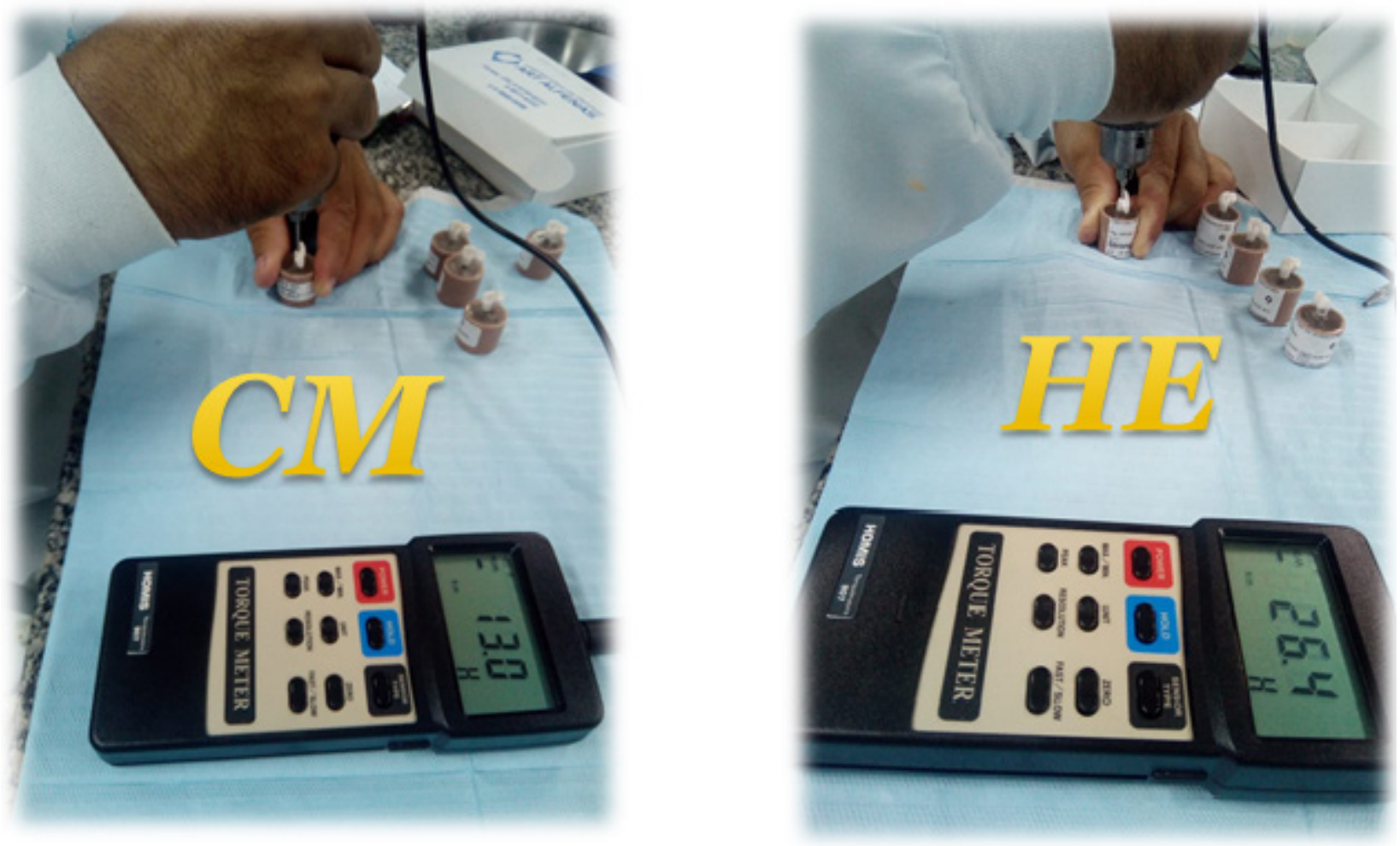

Source: Dental Materials Laboratory São Leopoldo Mandic.

Figure 12. Replacement of screws and torque to perform the second cycle (palatal 22).

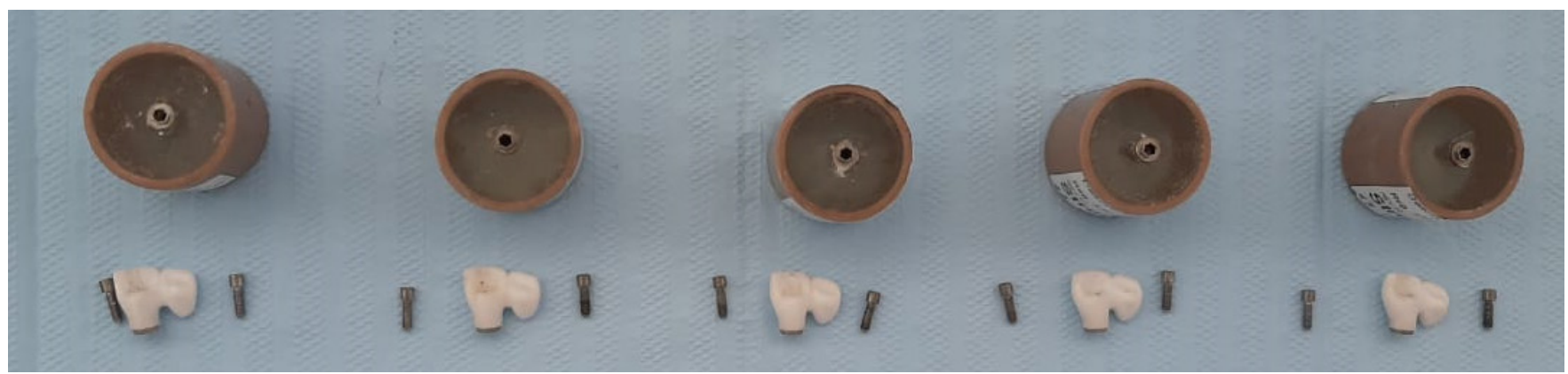

Source: Own authorship.

torque for all conditions: cone morse connection and force applied to the region of element $21(p<0.001)$ or 22 ( $p$ $<0.001$ ), or external hexagon implant and force applied to the region of element $21(p<0.001)$ or $22(p<0.001)$.

Regarding torque loss, two-way variance analysis showed no effect of the interaction between implant connection type and site of force application ( $p=0.094)$. This indicates that if cone morse and external hexagon implants differ in terms of torque loss, the effect is independent on site of force application (elements 21 or 22). Also, the lack of statistically significant interaction suggests that if torque loss is affected by the site of force 
application, this occured on the prosthetic screws of both cone morse and external hexagon implants.

There was also no significant difference between cone morse and external hexagon connection implants $(p=0.304)$ in terms of torque loss, regardless of site of force application (elements 21 or 22) (graph 1 and table 2). Torque loss was also not affected by site of force application $(p=0.241)$, regardless of connection implant type.

\section{DISCUSSION}

Student's $\mathrm{t}$ tests showed that removal torque was significantly smaller than initial torque. This result corroborates results by Ding et al. [4], Jorge et al. [5], Farina et al. [6], Koplin et al. [7], Sananez et al. [8], Benjaboonyazit et al. [9], Pereira et al. [10], Bulaqi et al. [11], and Martins et al. [12]. Nonetheless, studies by Cashman et al. [13] and

Graph 1. Bar diagram of initial torque, removal torque, and absolute torque loss for each implant type and site of force application in crowns with anterior cantilever.

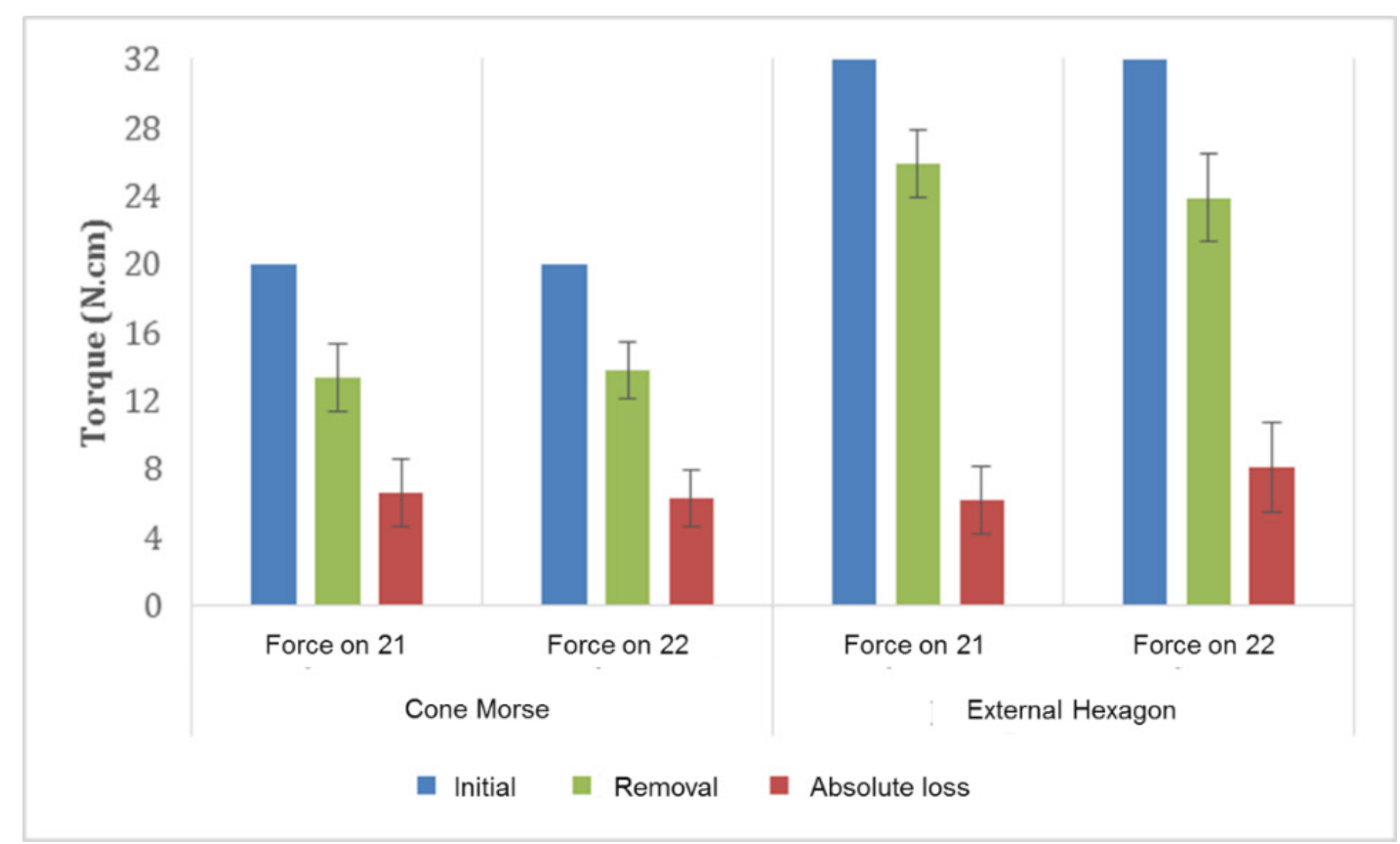

Source: Own authorship.

Table 2. Averages and standard deviations of removal torque and absolute and percent torque loss according to implant type and site of force application in crowns with anterior cantilever.

\begin{tabular}{|c|c|c|c|c|c|c|c|}
\hline \multirow{2}{*}{ Implant } & \multicolumn{2}{|c|}{ Removal Torque (N.cm) } & \multicolumn{2}{c|}{ Absolute Torque Loss (N.cm) } & \multicolumn{2}{c|}{ Relative Torque Loss (\%) } \\
\cline { 2 - 8 } & Force on 21 & Force on 22 & Force on 21 & Force on 22 & General average & Force on 21 & Force on 22 \\
\hline Cone Morse & $\mathbf{1 3 4}(\mathbf{2 0})$ & $\mathbf{1 3 . 8 ( 1 . 7 )}$ & $\mathbf{6 . 6 ( 2 0 )}$ & $\mathbf{6 . 3 ( 1 . 7 )}$ & $\mathbf{6 . 4 ( 1 . 8 ) A}$ & $\mathbf{3 3 . 0 \%}$ & $\mathbf{3 1 . 5 \%}$ \\
Extemal hexagon & $\mathbf{2 5 . 9 ( 2 0 )}$ & $\mathbf{2 3 . 9 ( 2 6 )}$ & $\mathbf{6 . 2 ( 2 0 )}$ & $\mathbf{8 . 1 ( 2 6 )}$ & $\mathbf{7 . 1 ( 2 5 ) \mathrm { A }}$ & $\mathbf{1 9 . 4 \%}$ & $\mathbf{2 5 . 3 \%}$ \\
\hline General average & - & - & $\mathbf{6 . 4 ( 2 0 ) a}$ & $\mathbf{7 . 2 ( 2 3 ) \mathrm { b }}$ & - & - & - \\
\hline
\end{tabular}

Source: Own authorship.

Caption: General averages followed by the same capital letter indicate lack of significant difference in absolute torque loss between cone morse and external hexagon implants, regardless of site of force application. General averages followed by the same lower case letter indicate lack of significant difference in absolute torque loss between force applied on element 21 and element 22, regardless of implant type. 
Silva et al. [14] contradict these results.

Regarding torque loss, two-way variance analysis showed no significant effect of the interaction between connection implant type and site of force application. Studies published by Ding et al. [4] Dittmer et al. [15], Silva et al. [16] and Taha et al. [3] report the same result. However, Villarinho et al. [16], Sananez et al. [8] and Kim et al. [17] disagree on the effect of the interaction between connection implant type and/or site of force application.

These two possible effects on torque loss were further investigated and analysis revealed that there is no significant difference between cone morse and external hexagon implants. Siadat et al. [18] found similar results studying screw loosening, although Santos et al. [19] and Shin et al. [20] showed an effect of the implant/abutment connection.

\section{CONCLUSION}

Data obtained after the cycling process showed that torque loss occurred both on $\mathrm{CM}$ and $\mathrm{EH}$ implants. There was no significant effect of the interaction between connection implants and site of force application.

\section{REFERENCES}

1- Mangano C, Mangano F, Piattelli A, lezzi G, Mangano A, La Colla L. Prospective clinical evaluation of 307 single-tooth morse taper-connection Implants: a multicenter study. Int J Oral Maxillofac Implants. 2010; 25 (2): 394-400

2- Bevilacqua M, Tealdo T, Menini M, Pera F, Mossolov A, Drago C, el al. The influence of cantiléver length and implant inclination on stress distribution in maxillaryimplantsupportedfixeddentures. 2011; 105(1):5-13. http://dx.doi.org/10.1016/S00223913(10)60182-5

3- Taha A, Al-Shahat MA, Ghazy M. Clinical and radiographicevaluations of implant-supported cantiléverfixedpartialdenturesreplacingmaxillary anterior teeth: A randomized clinical trial. J Prosthet Dent. 2020; 124(6):659666. http://dx.doi.org/10.1016/j.prosdent.2019.08.004

4- Ding TA, Woody RD, Higginbottom FL, Miller BH. Evaluation of the ITI Morse taper implant / abutment design with an internal modification. Int J Oral Maxillofac Implants. 2003;18(6): 865-72

5- Jorge JR, Barão VA, Delben JA, Assunção WG. The role of implant/abutment system on torque maintenance of retention screw and vertical misfit of implant-supported crows before and after mechanical cycling. Int J Oral Maxillofac Implants. 2013; 28 (2): 415-22. http://dx.doi.org/10.11607/jomi.2727
6- Farina AP, Spazzin AO, Consani RL, Mesquita MF. Screw joint stability after the application of retorque in implant-supported dentures under simulated masticatory conditions. J Prosthet Dent. 2014; 111 (6): 499-504

7- Koplin DC, Neto DJR, do Valle AC, Pereira JR. Influence of reverse torque values in abutments with orwithoutinternalhexagon indexes. J ProsthetDent. 2014; 112(4):824-7. http://dx.doi. org/10.1016/j.prosdent.2014.03.004

8- Sananez A, Lefebvre C, Looney S, Baker P, Mettenburg D, Rueggeberg F A. In vitro mechanical analysis of complete-arch mandibular implant-supported fixed prostheses abutment screw after cyclic loading. J Prosthet Dent. 2015; 113 (5): 432-9

9- Benjaboonyazit K, Chaijareenont $P$, Khongkhunthian P. Removal torque pattern of a combined cone and octalobule index implantabutment connection atdifferentcyclicloading: an in-vitro experimental study.International Journal of Implant Dentistry; Heidelberg. 2019; 5: 1-9. http://dx.doi.org/10.1186/ s40729-018-0154-2

10- Pereira PHS, Amaral M, Baroudi K, Vitti RP, Nassani MZ, Concílio LRS.Effect of Implant Platform Connection and Abutment Material on Removal Torque and Implant HexagonPlasticDeformation. Eur J Dent. 2019; 13(3):349-353. http://dx.doi.org/10.1055/s-0039-1700662

11- Bulaqi HA, Barzegar A, Paknejad M, Safari H. Assessment of preload, remaining torque, and removal torque in abutmentscrewsunderdifferentfrictionalconditions: A finiteelementanalysis. J Prosthet Dent. 2019; 121(3):548. http:// dx.doi.org/10.1016/j.prosdent.2018.10.035

12- Martins CM, Ramos EV, Kreve S, de Carvalho GA, Franco AB, de Macedo LG, et al. Reverse torque evaluation in indexed and nonindexedabutments of Morse Taper implants in a mechanical fatigue test. Dent Res J. 2019; 16:110-6

13- Cashman PM, Schneider RL, Schneider GB, Stanford CM, Clancy JM, Qian F. In vitro analisysis of post-fatigue reversetorque values at the dental abutment / implant interface for a unitarian abutment design. J Prosthodont. 2011; 20(7):503-9

14- Silva TSO, Alencar SMM, Valente VS, de Moura CDVS. Effect of internal hexagonal index on removal torque and tensileremoval force of different Morse taper connection abutments. J Prostet Dent. 2017; 117(5):621-627. http://dx.doi.org/10.1016/j. prosdent.2016.07.024

15- Dittmer MP, Dittmer S, Borchers L, Kohorst P, Stiesch M. Influence of the interface design on the yield force of the implant-abutment complex before and after cyclic mechanical loading. J Prosthodont Res. 2012; 56 (1): 19-24

16- Villarinho EA, Cervieri A, Shinkai RS, Grossi ML, Teixeira ER. The effect of a positioning index on the biomechanical stability of tapered implant-abutment connections. J Oral Implantol. 2015; 41 (2): 139-43

17- Kim S, Ku J, Kang D, Yun P, Yi Y, Kim Y. Clinical prognosis of single implant mesiodistal cantilévered prosthesis: A retrospective clinical study. Jornal de cirurgia oral e maxilofacial, medicina e patologia. 2018; 30(2):115-119. http://dx.doi.org/10.1016/j. ajoms.2017.09.007 
18- Siadat H, Najafi H, Alikhasi M, Falahi B, Beyabanaki E, Zayeri F. Efeito da carga cíclica oblíqua lateral na microinfiltração e afrouxamento do parafuso de implantes com diferentes conexões. J Dent Res Dent Clin Dent Perspectivas. 2018;12(3):183-189. http://dx.doi.org/10.15171/joddd.2018.028

19- Santos AM. Biomechanical study of prosthetic interfaces: A literature review. Dent Press Implantol. 2013;7(4):90-7

20- Shin HM, Hug JB, Yun MJ, Jeon YC, Chang BM, Jeong CM. Influence of the implant- abutment connection design and diameter on the screw joint stability. J Adv Prosthodont. 2014; 6 (2): 126-32. 